NASA/TM-2001-210664

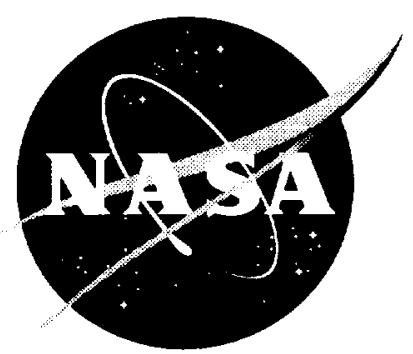

\title{
The Role of Molecular Weight and Temperature on the Elastic and Viscoelastic Properties of a Glassy Thermoplastic Polyimide
}

Lee M. Nicholson, Karen S. Whitley and Thomas S. Gates

Langley Research Center, Hampton, Virginia 
The use of trademarks or names of manufacturers in the report is for accurate reporting and does not constitute an official endorsement, either expressed or implied, of such products or manufacturers by the National Aeronautics and Space Administration.

Available from:

NASA Center for AeroSpace Information (CASI)

7121 Standard Drive

Hanover, MD 21076-1320

(301) 621-0390)
National Technical Information Service (NTIS)

5285 Port Royal Road

Springfield, VA 22161-2171

(703) 605-6000) 


\title{
The Role of Molecular Weight and Temperature on the Elastic and Viscoelastic Properties of a Glassy Thermoplastic Polyimide
}

\author{
Lee M. Nicholson', Karen S. Whitley, and Thomas S. Gates \\ NASA Langley Research Center, \\ Mechanics and Durability Branch, Structures \& Materials Competency \\ MS 188E, 2 West Reid Street, Hampton, VA 23681-2199
}

\begin{abstract}
Mechanical testing of the elastic and viscoelastic response of an advanced thermoplastic polyimide ( $\mathrm{LaRC}^{\mathrm{TM}}$-SI) with known variations in molecular weight was performed over a range of temperatures below the glass transition temperature. The notched tensile strength was shown to be a strong function of both molecular weight and temperature, whereas stiffness was only a strong function of temperature. A critical molecular weight was observed to occur at a weightaverage molecular weight of $\bar{M}_{1 "} \sim 22,000 \mathrm{~g} / \mathrm{mol}$ below which, the notched tensile strength decreases rapidly. This critical molecular weight transition is temperature-independent. Low molecular weight materials tended to fail in a brittle manner, whereas high molecular weight materials exhibited ductile failure. Furthermore, low molecular weight materials have increased creep compliance and creep compliance rate, and are more sensitive to temperature than the high molecular weight materials. At long timescales ( $>1100$ hours) physical ageing serves to significantly decrease the creep compliance and creep rate of all the materials tested. Low molecular weight materials are less influenced by the effects of physical ageing.
\end{abstract}

KEY WORDS: molecular weight, modulus, strength, creep-compliance, physical ageing, polyimides.

\section{Introduction}

Durability and long-term performance are among the primary concerns for the use of advanced polymer matrix composites (PMCs) in modern aerospace structural applications. For a PMC subjected to long-term exposure at elevated temperatures, the viscoelastic nature of the polymer matrix will contribute to macroscopic changes in composite stiffness, strength and fatigue life. Over time, changes in the polymer due to physical ageing will have profound effects on the viscoelastic compliance of the material, hence affecting its long-term durability [1]. Thus, the ability to predict material performance using intrinsic properties, such as molecular weight, would greatly enhance the efficiency of design and development of PMCs. It would be advantageous, therefore, if the effects of molecular weight could be accurately accounted for, such that a desired macroscopic mechanical response could be obtained from the material by optimizing specific parameters at the microscopic level.

Despite a wealth of literature on the molecular weight effects on the mechanical properties of glassy polymers [2-4], there is surprisingly little information addressing the role of molecular weight on the viscoelastic response of glassy polymers. Odani and others $[5,6]$ considered the effect of molecular weight distribution on the viscoelastic parameters of polystyrene and

\footnotetext{
' ICASE, Structures and Materials Division. NASA Langley Research Center, MS 1.32C, 3 West Reid Street. Hampton. VA 23681-2199.
} 
poly(cis-isoprene) derived from creep and relaxation measurements, along with viscosity data. More recently Plazek and others $[7,8]$ made creep and recoverable creep measurements on low molecular weight amorphous polystyrene and poly(methyl-phenyl-siloxane) and found that the steady state recoverable compliance decreased markedly with temperature as $T_{\mathrm{g}}$ was approached from above. Other workers have been trying to establish the effects of molecular weight on the unit cell free volume as a means for understanding physical ageing. Yu and others [9], and Singh and Eftekhari [10] have used positron annihilation lifetime spectroscopy to evaluate the free volume size and found that a decrease in molecular weight increases the cell's free volume.

The objective of this paper is to present the results of and discuss an experimental study that considers the effects of molecular weight and temperature on the elastic and viscoelastic behavior including physical ageing of an advanced polymer. Five distinct variations in molecular weight were used to evaluate the differences in mechanical performance of an advanced glassy thermoplastic polyimide. The physical ageing behavior was isolated by conducting sequenced, short-term isothermal creep compliance tests in tension. These tests were performed over a range of sub-glass transition temperatures. The material constants, material master curves and physical ageing-related parameters were evaluated as a function of temperature and molecular weight using time/temperature and time/ageing-time superposition techniques.

\section{Experimental Method}

\subsection{Materials}

The LaRC ${ }^{\mathrm{TM}}$-SI materials used in this study are thermoplastic amorphous polyimides and were prepared by Imitec Inc., Schenectady, NY. Extended synthesis descriptions of this material have been published elsewhere by Bryant et al.[11]. The molecular weights and intrinsic viscosities for LaRC ${ }^{\mathrm{TM}}$-SI were determined on the as-received powders using gel permeation chromatography by Siochi et al.[12]. The weight-average molecular weights $\left(\bar{M}_{1}\right)$ and the polydispersity indices $\left(\bar{M}_{n} / \bar{M}_{n}\right)$ of the materials are shown in Table 1, Siochi et al.[12]. Differential scanning calorimetry (DSC) was performed to determine the glass transition temperature of the molded material. The glass transition temperature was taken at the inflection point in the heat flow versus temperature curve.

The powder was dried to remove any residual solvents prior to being compression molded in air. Neat resin plaques were formed isothermally in a stainless steel mold at $340^{\circ} \mathrm{C}$ for one hour under $3.1 \mathrm{MPa}$ of pressure. Rectangular test coupons measuring approximately $150 \times 17.5 \times 5.8$ $\mathrm{mm}$ were machined from the plaques.

\subsection{Mechanical Test Instrumentation and Procedures}

\subsubsection{Elastic Properties: Monotonic Tensile Loading}

Monotonic tensile tests were performed at six specific test temperatures below the glass transition temperature $\left(T_{g}\right)$. To place equal emphasis on the results, due to the different $T_{g} s$ of the materials, the test temperature is referenced to the glass transition temperature. The reduced temperature is defined as: $\Delta T=T_{s}-T_{t e x}$. Uniaxial tensile tests were performed using a $22.2 \mathrm{kN}$ servo-hydraulic test system equipped with a heated test chamber. A tensile load was applied at a constant ramp rate of $22.2 \mathrm{~N} / \mathrm{s}$, under isothermal conditions. The tests were terminated when failure occurred or the maximum permissible elongation was achieved. 
A high-temperature strain gage was applied to each specimen in a direction transverse to the length, on one face, to record the transverse strain. Longitudinal strain was measured using a high-temperature extensometer mounted on the thin edge of the specimen. The engineering stress was determined from the load measured by the servo-hydraulic system's load cell divided by the average unnotched cross-sectional area measured prior to the test.

Young's Modulus, (E) was calculated using Equation (1) from the least squares fit to the slope of the linear portion of the stress $(\sigma)$ versus the longitudinal strain $\left(\varepsilon_{\mathrm{x}}\right)$ curve, fitting through the origin. Similarly, Poisson's Ratio (v), equation (2), was calculated as the slope of the transverse strain $\left(\varepsilon_{y}\right)$ versus the longitudinal strain in the same linear region. The Shear Modulus $(G)$ was calculated in terms of $E$ and $v$ using equation (3).

$$
\begin{gathered}
E=\frac{\sigma_{1}}{\varepsilon_{i}} \\
v=-\frac{\varepsilon_{1}}{\varepsilon_{v}} \\
G=\frac{E}{2(1+v)}
\end{gathered}
$$

To facilitate a controlled failure, an edge notch was cut in the specimen using a jeweler's blade $(0.38 \mathrm{~mm}$ width) mounted on a handsaw. Tensile strength was calculated from the maximum load achieved during the tensile test divided by the original, unnotched cross sectional area. For a given molecular weight, two tests at each temperature were performed using the notched specimen geometry. Photomicrographs with a magnification of $25 \mathrm{x}$, were taken of the notched surface after failure to determine the morphology of the failure surface.

\subsubsection{Viscoelastic Properties: Tensile Creep Compliance Tests}

Tensile creep tests were performed at three specific test temperatures below the glass transition temperature $\left(\Delta \mathrm{T}=25,20,15^{\circ} \mathrm{C}\right)$. Listed in Table 1 , these test temperatures were selected to ensure that measurable physical ageing occurred within the test period.

The tensile creep tests were performed in a convection oven equipped with a digital controller. Tensile load was applied through a uniaxially symmetric dead-weight system. Strain was measured with high-temperature strain gages applied in a longitudinal direction, on each face of the specimen. Apparent thermal strain was corrected by using the compensating gage technique established by Murry et al. [13].

Determination of the stress level necessary to stay within the linear viscoelast ic strain range was made by checking that the proportionality condition and Boltzmann's superposition (Findley et al. [14]) would be satisfied. Creep and creep-recovery tests provided data for checking superposition.

\subsubsection{Short-term Momentary and Long-term Creep Compliance Tests}

To establish the effects of physical ageing on the viscoelastic properties, a well-documented technique that measures the momentary creep compliance as described in Struik [15] was used 
for all tests. This procedure consisted of a periodic sequence of creep, under constant load, and recovery tests while the specimen isothermally ages.

For these momentary tests, the duration of each creep segment was $1 / 10$ th the duration of the prior total ageing time. The ageing times (time after quench) selected for starting each creep segment were $2,4,8,24,48,72$ and 96 hours, respectively. After each creep segment, the specimen was unloaded and allowed to recover until the start of the next creep segment. To account for any remaining residual strain due to a lack of complete recovery, the strain measured in the creep segment was corrected by subtracting the extrapolated recovery strain from the prior creep curve.

To establish how long-term creep is influenced by molecular weight and physical ageing, longterm ( $>1100$ hours) tests were performed. For the long-term tests, specimens were aged for 2 hours (h) prior the application of load. The applied load provided the same stress condition as used in the short-term sequenced creep compliance tests.

To provide for the test condition that all specimens start the test sequence in the same unaged condition, specimen rejuvenation was followed according to Struik [15]. In the current tests, the gauged specimen was heated to $10^{\circ} \mathrm{C}$ above the $\mathrm{T}_{\mathrm{g}}$ (for each material offset) and held isothermally for 15 minutes, immediately before the start of any physical ageing test sequence. High-pressure cool air was used to quench the specimen to below the $T_{g}$. Upon reaching the desired test temperature, the material ageing starts and the time is recorded.

\subsection{Analysis of viscoelastic behavior and ageing}

The time-dependent linear creep compliance was modeled with a three-parameter KolrauschWilliams-Watts (KWW) [16, 17] expression given by,

$$
S(t)=S_{n} e^{(l / \tau)^{\beta}}
$$

where $S_{\iota}, t, \tau$, and $\beta$ are the initial compliance, time, retardation time and shape parameter of the distribution of molecular relaxation times, respectively. The three material parameters were found from curve fits of Equation (4) to sequenced short-term creep and recovery tests.

Due to physical ageing of the polymer, the momentary creep compliance curves are separated by time shifts related to the degree of ageing. Therefore, time-ageing time superposition of the test data provided the means for the sequenced, short-term data to be collapsed into a single momentary master curve (MMC) at each test temperature. As demonstrated by Struik [15], physical ageing can be characterized by the ageing shift factor $a$, which is simply defined as the horizontal distance required to shift a creep compliance curve along the time axis to coincide with a reference creep compliance curve. The reference creep compliance curve could be any of the sequenced curves, but for convenience of data manipulation, the longest ( 96 hours) creep compliance curve was selected as the reference during formation of the MMC. A linear fit of the logarithm of all the shift factors $(\log a)$ versus the logarithmic ageing time $\left(\log t_{e}\right)$ for each $\mathrm{MMC}$, gave the ageing shift rate, $\mu$ :

$$
\mu=\frac{-d \log a}{d \log t}
$$


where $t_{e}$ is the ageing time. Ageing shift rates $(\mu)$ were calculated for all cases using the sets of master curves. These calculated values are given in Table 2. For any ageing time $\left(t_{e}\right)$ the ageing time shift factor can be written as

$$
a_{t}=\left(\frac{t_{t r_{c} t}}{t_{t \cdot}}\right)^{M}
$$

where $t_{\text {tret }}$ is the reference ageing time, introduced by Brinson et $a l$. [18].

Any creep compliance curve can be translated to a new reference time. For a horizontal (log time) translation of a compliance curve, only the retardation time parameter needs to be recalculated. Given the ageing shift rate and reference curve parameters, the translation from one ageing time to another was accomplished through the use of Equation 7:

$$
\tau_{r}=\tau_{r e f}\left(\frac{t_{r}}{t_{\text {eret }}}\right)^{\mu \prime}
$$

To facilitate the collapse of the shifted data for the momentary master curve (MMC), vertical (compliance) shifts were also utilized. This use of small vertical shifts in reduction of PMC tensile creep compliance/ageing data was also reported $[19,20]$. The vertical shifts for all data sets were small in comparison to the magnitude of the corresponding horizontal (time) shifts. No clear trends existed in these vertical shifts and analysis of vertical shift factors versus ageing time did not lend itself to developing a constant vertical shift rate. A computer code, written by Bradshaw [21], was used to help collapse the short-term creep compliance curves into a master curve and generate the associated master curve and physical ageing parameters using both horizontal and vertical shifting.

Isothermal momentary master curves (MMCs) can be further reduced to a single master curve through the use of time-temperature superposition. The use of time-temperature superposition (TTSP), established by Leaderman and later by Findley et al. [14, 22], requires that creep compliance be a function of temperature $(T)$ and time $(t)$ such that

$$
S(t)=S(T, t)=S\left(T_{o}, \zeta\right)
$$

and that

$$
\varsigma=t / a_{T}(T)
$$

where $\varsigma$ is the reduced time that is related to the real time $t$ by the temperature shift factor $a_{T}(T)$, where $T_{1}$ is the reference temperature.

For this study, the collection of individual MMCs for each temperature per molecular weight were collapsed into single material master curves using TTSP. The collapse was made using a single reference curve and horizontal (time) shifts only. The TTSP master curves for each molecular weight offset were consolidated using a reduced reference temperature of $\Delta \mathrm{T}=20^{\circ} \mathrm{C}$. The three curve fit parameters used to characterize each of the MMCs are given in Table 2. 


\section{Results And Discussion}

\subsection{Elastic Properties}

The experimental results are presented for the mechanical behavior on the $\mathrm{LaRC}^{\mathrm{TM}}-\mathrm{SI}$ specimens. The effects of variations in test temperature and molecular weight were examined for each property of interest. The error bars indicate the standard deviation of averaged results. In a previous work by Nicholson et al. [23] that evaluated the effects of molecular weight on the elastic (time-independent) properties of $\mathrm{LaRC}^{\mathrm{TM}}-\mathrm{SI}$, a clear distinction in the mechanical properties between high and low molecular weights was discovered. Therefore, the same classification will be adopted in this study: the high molecular weight materials are considered to be the $1-3 \%$ offsets $(51,070-24,290 \mathrm{~g} / \mathrm{mol})$ and the low molecular weight materials are the 4 $5 \%$ offsets $(21,180-15,880 \mathrm{~g} / \mathrm{mol})$.

Typical stress-strain curves obtained from unnotched specimens with various molecular weights, tested at the highest test-temperature of $15^{\circ} \mathrm{C}$ below $T_{\underline{g}}\left(\Delta T=15^{\circ} \mathrm{C}\right)$ are displayed in Figure la. Curves were truncated at $2.5 \%$ strain and those curves that terminate before this value, indicate failure occurred in the sample. It can be seen that the failure strains are over $0.5 \%$ for low molecular weights and the higher molecular weights have strains of at least $2.5 \%$. A high degree of curvature indicates non-linear elastic deformation at the higher strains.

The stress-strain response for a high molecular weight (1\%) material was plotted to display the effect of temperature, as shown in Figure $1 \mathrm{~b}$. The graph shows an increase in compliance with increasing temperature and exhibits good elongation to failure when compared to the lower molecular weight material in Figure la.

Young's Modulus (E) and Shear Modulus (G) versus temperature are given in Figure 2. As expected, both $\mathrm{E}$ and $\mathrm{G}$ decrease as temperature is raised. The rate of change of $\mathrm{E}$ with temperature is fairly uniform up to $200^{\circ} \mathrm{C}$. From $200^{\circ} \mathrm{C}$ to the highest temperature $\left(\sim 235^{\circ} \mathrm{C}\right)$ there was a sharp decrease in modulus because the temperature was in the vicinity of the $T_{g}$ of the material. Similar to $E$, there is a uniform decrease in $G$ as the temperature is raised, but with a shallower gradient. The start of the sharp decrease in modulus occurs at a higher temperature of $\sim 220^{\circ} \mathrm{C}$.

Graphs of notched tensile strength (NTS) versus temperature and molecular weight are shown in Figure $2 b$ and Figure $3 b$, respectively. Figure $2 b$ illustrates the marked dependence of NTS on temperature. Thus, it is shown that NTS decreases as temperature increases. Over the range from room temperature to $150^{\circ} \mathrm{C}$, the two highest molecular weight materials show good strength stability compared to the lower molecular weight materials, which show a steep decrease in strength with increase in temperature. However, in the range from $150^{\circ} \mathrm{C}$ to $230^{\circ} \mathrm{C}$ the converse is true, with the lower molecular weight materials showing little or no temperature-dependency on NTS. The NTS of the high molecular weight materials is seen to decline rapidly in this high temperature region. The different molecular weight series are fitted with least squares quadratic polynomials to indicate the nonlinear mechanical response as temperature is raised.

The NTS data plotted as a function of molecular weight, as shown in Figure 3b, have been fitted with least squares sigmoid curves for each temperature series. It can be seen that there is a sharp increase in NTS occurring at $22,000 \mathrm{~g} / \mathrm{mol}$ weight-average molecular weight. At molecular weights higher than this "critical molecular weight" $\left(M_{c}\right)$ transition, the NTS is increased and 
conversely, at lower molecular weights $\left(\bar{M}_{n}<22,000 \mathrm{~g} / \mathrm{mol}\right)$, the NTS is drastically reduced. Furthermore, it is shown that this critical molecular weight transition is not temperaturedependent. The percentage change in NTS, in going from $\bar{M}_{n}=15,880 \mathrm{~g} / \mathrm{mol}$ to $\bar{M}_{n}=41,100$ $\mathrm{g} / \mathrm{mol}$, (i.e. across the transition) for successively increasing temperatures, is seen to increase with temperature from approximately $200 \%$ at room temperature up to nearly $900 \%$ at $\Delta \mathrm{T}=$ $45^{\circ} \mathrm{C}$.

\subsection{Fractography}

The fracture surfaces of each specimen were examined to assess the involvement of different molecular weight-dependent failure mechanisms. Optical photomicrographs of the notched surface after failure are provided in Figure 3 a for the extremes in molecular weight and temperature - the notch is at the top of each image. The image at top left (high $M_{n}$, low $T$ ) shows evidence of many parabolic markings (or 'dimple rupture' in metals parlance). The image at the top right (high $M_{1}$, high $T$ ) illustrates a relatively smooth, glasslike surface with striations, hackles and arrest lines. The lower left image (low $M_{w}$, low $T$ ) shows a rough surface with no parabolic markings, but the presence of three-dimensional surface-substructures with smooth regions interspersed. This indicates the likelihood of fast crack propagation and is similar to those fracture surfaces observed by Cantwell et al.[24] in epoxy resins with single edge notch geometry and a blunt pre-crack. The lower right image (low $M_{n}$, high $T$ ) is relatively smooth, but not glasslike, and contains many tear-sites or voids. In addition, the crack front is seen to have propagated in a concentric circular fashion, which is indicative of a stable or constant velocity crack front. Hence, it is clear, from Figure $3 a$, that there are distinct differences in the failure events for different molecular weight materials as a function of temperature.

\subsection{Viscoelastic Properties}

\subsection{Momentary Creep Compliance Curves}

All results have been examined by comparing the viscoelastic creep compliance versus time as a function of temperature and molecular weight. In the following results, a comparison of properties will be given in terms of one high and one low molecular weight material, viz. $2 \%$ $(41,100 \mathrm{~g} / \mathrm{mol})$ and $5 \%(15,880 \mathrm{~g} / \mathrm{mol})$.

The momentary creep compliance curves are plotted as a function of time: for a low molecular weight material (5\%) at three reduced temperatures in Figure 4. Common to all temperatures and all molecular weights is the fact that an increase in ageing time generally decreases the overall creep compliance and also the creep rate. This is exemplified in Figure $4 \mathrm{a}$ where the $2 \mathrm{~h}$ ageing time curve attains the same log creep compliance of $-0.25 \mathrm{GPa}^{-1}$ after $800 \mathrm{~s}$, as the $96 \mathrm{~h}$ ageing time curve after nearly $50,000 \mathrm{~s}$, notwithstanding the decrease in initial creep compliance in moving from the $2 \mathrm{~h}$ to $96 \mathrm{~h}$ ageing time curve. Thus, the specimen stiffness increases with ageing time.

It can also be seen that there is an increase in creep rate with increase in temperature by comparing Figure $4 \mathrm{a}$ with Figure $4 \mathrm{c}$. For example, in Figure $4 \mathrm{a}$, it takes the $96 \mathrm{~h}$ ageing time curve $\sim 50,000 \mathrm{~s}$ to attain a log creep compliance of $-0.25 \mathrm{GPa}^{-1}$, whereas in Figure $4 \mathrm{~b}$ and Figure $4 \mathrm{c}$, it takes $\sim 20,000 \mathrm{~s}$ and $\sim 9,000 \mathrm{~s}$, respectively, to reach this value. There are some creep curves that cross over each other and this occurs when a lower ageing time curve has a 
lower initial compliance than a higher ageing time curve; this was attributed to experimental scatter in the data.

\subsubsection{Creep Compliance Momentary Master Curves (MMCs)}

A comparison of the creep compliance MMCs for the high and low molecular weight materials is plotted as a function of time at the three equivalent reduced temperatures in Figure 5 . The three MMC parameters $\left(S_{c}, \tau\right.$ and $\beta$ ), given in Table 2, were found by fitting Equation 4 to the collapsed momentary data sets. Common to Figure $5 \mathrm{a}$ and Figure $5 \mathrm{~b}$ is the relationship of increased compliance with increase in temperature, and also increase in creep rate with increase in temperature.

There is a clear difference in the creep rates when comparing the low and high molecular weight material at the highest temperature. Aside from the slightly lower initial creep compliance of the lower molecular weight material, the low molecular weight material has a higher creep rate than the high molecular weight material. In Figure 5b (low molecular weight), the high temperature curve reaches a log creep compliance of $0.44 \mathrm{GPa}^{-1}$, but the high temperature curve in Figure $5 \mathrm{a}$ (high molecular weight) reaches only $0.26 \mathrm{GPa}^{-1}$. This increase in the rate of creep compliance with decrease in molecular weight has also been seen in other glassy thermoplastic materials [5, $25]$.

\subsubsection{Time-temperature superposition shift factors}

The TTSP shift factors are the horizontal time shifts that are required to shift the MMC data, plotted in Figure 5, to the reference temperature of $\Delta T=20^{\circ} \mathrm{C}$. In Figure 6 , these TTSP shift factors are plotted as a function of reduced temperature for all molecular weights. It can be seen that the TTSP shift factors decrease as temperature increases towards $T_{g}$ for all molecular weights. Therefore, the time shift required to collapse a creep compliance curve to the reference temperature curve decreases with increase in temperature as it approaches $T_{g}$. In this instance, the high temperature creep compliance curve requires less horizontal time shift than the low temperature creep compliance curve.

At higher temperatures, the polymer chains have increased mobility and the time it takes the material to creep is therefore decreased. Furthermore, at the highest test temperature $\left(\Delta \mathrm{T}=15^{\circ} \mathrm{C}\right)$, there is a clear separation between high and low molecular weight TTSP shift factors.

By plotting this data (Figure 6a) as a function of molecular weight, an indication of the temperature sensitivity of the creep compliance for each molecular weight will be obtained. The slope, or rate of change of TTSP shift factor with respect to temperature is given in Equation 10 as:

$$
\delta_{T}=\frac{-d \log a_{r}}{d T}
$$

Figure $6 \mathrm{~b}$ summarizes the different materials' behavior. Thus, the high molecular weight materials are seen to be less sensitive to temperature as compared with the low molecular weight materials. There appears to be a distinct molecular weight transition that occurs below 25 $\mathrm{kg} / \mathrm{mol}$, so materials that have a molecular weight less than this value will show increased sensitivity to temperature in the timescale of their viscoelastic responses. 


\subsubsection{Long-term Creep Compliance}

The long-term creep compliance of the material was investigated using a $2 \mathrm{~h}$ ageing time (used as the reference ageing time) prior to the application of constant load for the duration of $\sim 1100$ hours $\left(\sim 4 \times 10^{6} \mathrm{~s}\right)$. The effects of both test temperature and molecular weight on long-term test data are conveniently summarized in Figure 7 . The effect of increasing the temperature is to increase the creep compliance and creep rate, in accord with the short-term creep compliance data. By varying molecular weight on the long-term viscoelastic response, it is the low molecular weight materials that show increased creep compliance and creep rate over the high molecular weight materials. Upon closer examination of the two different data sets, it can be seen that the incipient separation between the high and low molecular weight materials happens approximately three times faster for a high test temperature $(\sim 600$ s) versus a low test temperature $(2,000 \mathrm{~s})$.

\section{Conclusions}

Mechanical testing of the elastic and viscoelastic response of an advanced thermoplastic polyimide ( $\mathrm{LaRC}^{\mathrm{TM}}-\mathrm{SI}$ ) with known variations in molecular weight was performed over a range of temperatures below the glass transition temperature.

The notched tensile strength is a strong function of both temperature and molecular weight. A critical molecular weight $\left(M_{t}\right)$ is observed to occur at a $\bar{M}_{n} \sim 22,000 \mathrm{~g} / \mathrm{mol}$ below which, the notched tensile strength decreases rapidly. This critical molecular weight transition is not temperature dependent. The observed microstructures have helped to characterize the fracture event as a function of molecular weight and temperature. Independent of temperature, the high molecular weight materials $\left(\bar{M}_{n}>M_{i}\right)$ tend to fail in a ductile manner, whereas the low molecular weight materials $\left(\bar{M}_{n}<M_{c}\right)$ exhibit brittle failure. The Young's and Shear Moduli reveal only temperature dependence.

The short term (96 hours) creep compliance tests, run over a range of sub- $T_{g}$ temperatures, provided material constants, material master curves and ageing-related parameters. The timetemperature superposition analysis of the creep compliance showed that low molecular weight materials have increased creep compliance and increased creep rate, than that seen in the high molecular weight materials. Furthermore, the temperature sensitivity of the TTSP shift factor is dramatically increased for molecular weights less than $\bar{M}_{n} \sim 25 \mathrm{~kg} / \mathrm{mol}$.

The effects of creep loading for long timescales ( $>1100$ hours) provided a means for evaluating the long-term effects of molecular weight and temperature. A decrease in the molecular weight and an increase in the temperature both serve to increase the creep compliance and creep rate.

Thus, for any given temperature, the effect of reducing the molecular weight is somewhat akin to raising the test temperature: the creep compliance and creep rate are increased. It is likely, then, that the polymer segmental mobility is higher in a low molecular weight material since it is not hindered as much by the presence of physical entanglements. This increase in segmental mobility is associated with more available free volume in which to move. Therefore, for a constant temperature over long timescales, the low molecular weight materials are less influenced by physical aging. 


\section{Acknowledgements}

The authors are grateful for: discussions with Dr. S. W. Smith and Dr. R. S. Piascik on the fractography; the provision of materials from Imitec, Inc.; the gel permeation chromatography performed by Dr. E. J. Siochi; and the technical assistance of Mr. C. E. Townsley and Mr. R. T. Razon. This work was performed while Dr. Nicholson held a National Research Council Research Associateship at NASA Langley Research Center.

\section{References}

[1] McKenna GB. On the physics required for prediction of long-term performance of polymers and their composites. J. Res. Nat. Inst. Stand. Tech. 1994;99(2):169-89.

[2] Vincent PI. A correlation between critical tensile strength and polymer cross-sectional area. Polymer 1972;13:558-60.

[3] Kusy RP, Turner DT. Influence of molecular-weight of poly(methyl methacrylate) on fracture morphology in notched tension. Polymer 1977;18(4):391-402.

[4] Prentice P. The influence of molecular weight on the fracture of thermoplastic glassy polymers. J. Mater. Sci. 1985;20(4):1445-54.

[5] Nemoto N, Moriwaki M, Odani H, Kurata M. Viscoelastic properties of narrow-distribution polymers. 3. Shear creep studies of narrow-distribution poly (cis-isoprene). Macromolecules $1971 ; 4: 215-20$.

[6] Odani H, Nemoto N, Kurata M. The viscoelastic properties of undiluted linear polymers of narrow molecular weight distribution in the terminal zone. Bull. Inst. Chem. Res., Kyoto Univ. 1972;50(2):117-33.

[7] Ngai KL, Plazek DJ, Bero CA. Viscoelastic properties of amorphous polymers 2: Anomalous temperature dependence of the steady-state recoverable compliance in low molecular weight polymers. Macromolecules 1993;26(5):1065-71.

[8] Plazek DJ, Bero CA, Neumeister S, Floudas G, Fytas G, Ngai KL. Viscoelastic properties of amorphous polymers 3: Low molecular weight poly(methylphenylsiloxane). Colloid and Polym. Sci. 1994;272(11):1430-8.

[9] Yu Z, Yashi U, McGervey JD, Jamieson AM, Simha R. Molecular weight-dependence of free volume in polystyrene studied by positron annihilation measurements. J. Polym. Sci. Polym. Phys. 1994;32(16):2637-44.

[10] Singh JJ, Eftekhari A. Free volume model for molecular weights of polymers. Nuclear Instruments \& Methods in Physics Research 1992;B63:477-83.

[11] Bryant RG. LARC-SI: a soluble aromatic polyimide. High Perform. Polym. 1996;8(4):60715.

[12] Siochi EJ, Young PR, Bryant RG. In: Materials Challenge - Diversification and the Future. SAMPE, Los Angeles, California, 1995, vol. 40(1), pp. 11-8.

[13] Murry WM, and Miller, WR. The Bonded Electrical Resistance Strain Gage. New York: Oxford University Press, 1992.

[14] Leaderman H. Elastic and creep properties of filamentous materials and other high polymers. Washington, D.C.: Textile Foundation, 1943.

[15] Struik LCE. Physical Aging in Amorphous Polymers and Other Materials. New York: Elsevier Scientific Publishing Company, 1978.

[16] Kohlrausch R. In: Annalen der Physik und Chemie. Poggendorf JC, ed. 1854, vol. 91, pp. 179-214. 
[17] Williams G, Watts DC. Nonsymmetrical dielectric relaxation behavior arising from a simple empirical decay function. Trans. Faraday Soc. 1970;66:80-5.

[18] Brinson LC, Gates TS. Effects of physical aging on long term creep of polymers and polymer matrix composites. Int. J. Solids Struct. 1995;32:827-46.

[19] McKenna GB, Leterrier Y, Schultheisz CR. In: Use of Plastics and Plastic Composites: Materials and Mechanics Issues. Stokes YK, ed. The American Society of Mechanical Engineers, 1993, vol. MD-46,.

[20] Hastie RL, Morris DH. In: High Temperature and Environmental Effects in Polymer Matrix Composites. Harris CE, Gates TS, eds. American Society for Testing and Materials, Philadelphia, 1992, vol. ASTM STP 1174, pp. 163-85.

[21] Bradshaw RD, Brinson LC. Physical Aging in Polymers and Polymer Composites: An Analysis and Method for Time-Aging Time Superposition. Polymer Engineering and Science 1997;37(1):31-44.

[22] Findley WN, Lai JS, Onaran K. Creep and Relaxation of Nonlinear Viscoelastic Materials. Toronto: North-Holland Publishing Company, 1976.

[23] Nicholson LM, Whitley KS, Gates TS, Hinkley JA. How molecular structure affects mechanical properties of an advanced polymer. In: Proceedings of SAMPE, Long Beach, CA, 1999: vol. 44(1): 794-808.

[24] Cantwell WJ, Roulin-Moloney AC. In: Fractography and failure mechanisms of polymers and composites. Roulin-Moloney AC, ed. Elsevier Science Publishers Ltd, London, 1989 pp. 233-90.

[25] Fujimoto T, Ozaki N, Nagasawa M. Stress relaxation of monodisperse poly(amethylstyrene). J. Polym. Sci. A2 1968;6:129-35. 
Table 1. Weight-Average Molecular Weights $\left(\bar{M}_{n}\right)$, Polydispersity Indices $\left(\bar{M}_{n} / \bar{M}_{n}\right)$, Glass Transition Temperatures ( $T_{\mathrm{g}} \mathrm{s}$ ) And Mechanical Test Temperatures Of Various LaRC ${ }^{\mathrm{TM}}-\mathrm{SI}$ Materials.

\begin{tabular}{|c|c|c|c|c|c|c|c|c|c|}
\hline $\begin{array}{l}\text { Offset } \\
\%\end{array}$ & $\begin{array}{c}\bar{M}_{w} \\
{[\mathrm{~g} / \mathrm{mol}]}\end{array}$ & $\frac{\bar{M}_{w}}{\bar{M}_{n}}$ & $\begin{array}{c}\mathrm{T}_{y} \\
\text { (DSC) } \\
\text { ("Cl }\end{array}$ & $\begin{array}{c}\Delta T=15 \\
I^{\circ} \mathrm{Cl}\end{array}$ & $\begin{array}{c}\Delta T=20 \\
{[\mathrm{C}]}\end{array}$ & $\begin{array}{c}\Delta \mathrm{T}=25 \\
{\left[{ }^{\mathrm{c} C}\right]}\end{array}$ & $\begin{array}{c}\Delta \mathrm{T}=45 \\
{\left[{ }^{\prime \prime} \mathrm{C}\right]}\end{array}$ & $\begin{array}{c}\Delta \mathrm{T}=70 \\
\mid \mathrm{Cl}\end{array}$ & $\begin{array}{c}\Delta \mathrm{T}=120 \\
{\left[{ }^{\circ} \mathrm{C}\right]}\end{array}$ \\
\hline 1 & 51070 & 4.57 & 248 & 235 & 230 & 225 & 205 & 180 & 130 \\
\hline 2 & 41100 & 2.98 & 248 & 231 & 226 & 221 & 201 & 176 & 126 \\
\hline 3 & 24290 & 2.3() & 242 & 223 & 218 & 213 & 193 & 168 & 118 \\
\hline 4 & 21180 & 2.14 & 230 & 223 & 218 & 213 & 193 & 177 & 126 \\
\hline 5 & 15880 & 1.79 & 231 & 219 & 214 & 209 & 189 & 164 & 114 \\
\hline
\end{tabular}

Table 2. Momentary Master Curve Parameters And TTSP Shift Factors For All Molecular Weight LaRC ${ }^{\mathrm{TM}}-$ SI Materials.

\begin{tabular}{|c|c|c|c|c|c|c|c|c|}
\hline $\begin{array}{c}\% \\
\text { Offset }\end{array}$ & $\begin{array}{c}\bar{M}_{n} \\
{[\mathrm{~g} / \mathrm{mol}]}\end{array}$ & $\begin{array}{l}\mathrm{T}_{1 \mathrm{w} \mid} \\
|\mathrm{C}|\end{array}$ & $\begin{array}{c}\Delta \mathrm{T} \\
1^{\circ} \mathrm{Cl}\end{array}$ & $\begin{array}{c}S_{\prime \prime} \\
\left|\mathrm{GPa}^{-1}\right|\end{array}$ & $\tau(\mathrm{s})$ & $\beta$ & $\mu$ & $\mathbf{a}_{\mathbf{T}}$ \\
\hline \multirow[t]{3}{*}{1} & \multirow[t]{3}{*}{51070} & 225 & 25 & 0.404 & $7.30 \mathrm{E}+05$ & 0.397 & 1.080 & 0.410 \\
\hline & & 230 & 20 & 0.402 & $2.72 \mathrm{E}+05$ & 0.401 & 0.994 & 0.000 \\
\hline & & 235 & 15 & 0.339 & $7.30 \mathrm{E}+04$ & 0.392 & 0.881 & $0.30^{4}$ \\
\hline \multirow[t]{3}{*}{2} & \multirow[t]{3}{*}{41100} & 221 & 25 & 0.385 & $4.71 \mathrm{E}+0.5$ & 0.419 & 0.966 & 0.310 \\
\hline & & 226 & 20 & 0.401 & $2.85 E+0.5$ & 0.407 & 0.979 & 0.000 \\
\hline & & 231 & 15 & 0.398 & $1.31 \mathrm{E}+05$ & 0.406 & 0.998 & 0.350 \\
\hline \multirow[t]{3}{*}{3} & \multirow[t]{3}{*}{24290} & 213 & 25 & 0.375 & $8.51 \mathrm{E}+05$ & 0.375 & 0.991 & 0.310 \\
\hline & & 218 & 20 & 0.371 & $3.21 \mathrm{E}+(05$ & 0.411 & 0.922 & 0.000 \\
\hline & & 223 & 15 & 0.313 & $1.52 \mathrm{E}+05$ & 0.40 .3 & 0.946 & 0.310 \\
\hline \multirow[t]{3}{*}{4} & \multirow[t]{3}{*}{21180} & 213 & 25 & 0.355 & $3.61 E+05$ & 0.369 & 0.969 & 0.600 \\
\hline & & 218 & 20 & 0.373 & $9.68 \mathrm{E}+04$ & 0.358 & 0.904 & 0.000 \\
\hline & & 223 & 15 & 0.295 & $1.03 \mathrm{E}+04$ & 0.204 & 0.827 & 0.610 \\
\hline \multirow[t]{3}{*}{5} & \multirow[t]{3}{*}{15880} & 209 & 25 & 0.361 & $4.91 \mathrm{E}+05$ & 0.392 & 0.999 & 0.360 \\
\hline & & 214 & 20) & 0.353 & $2.13 \mathrm{E}+0.5$ & 0.395 & 0.914 & 0.000 \\
\hline & & 219 & 15 & 0.373 & $6.67 E+(04$ & 0.386 & 0.880 & 0.610 \\
\hline
\end{tabular}


a)
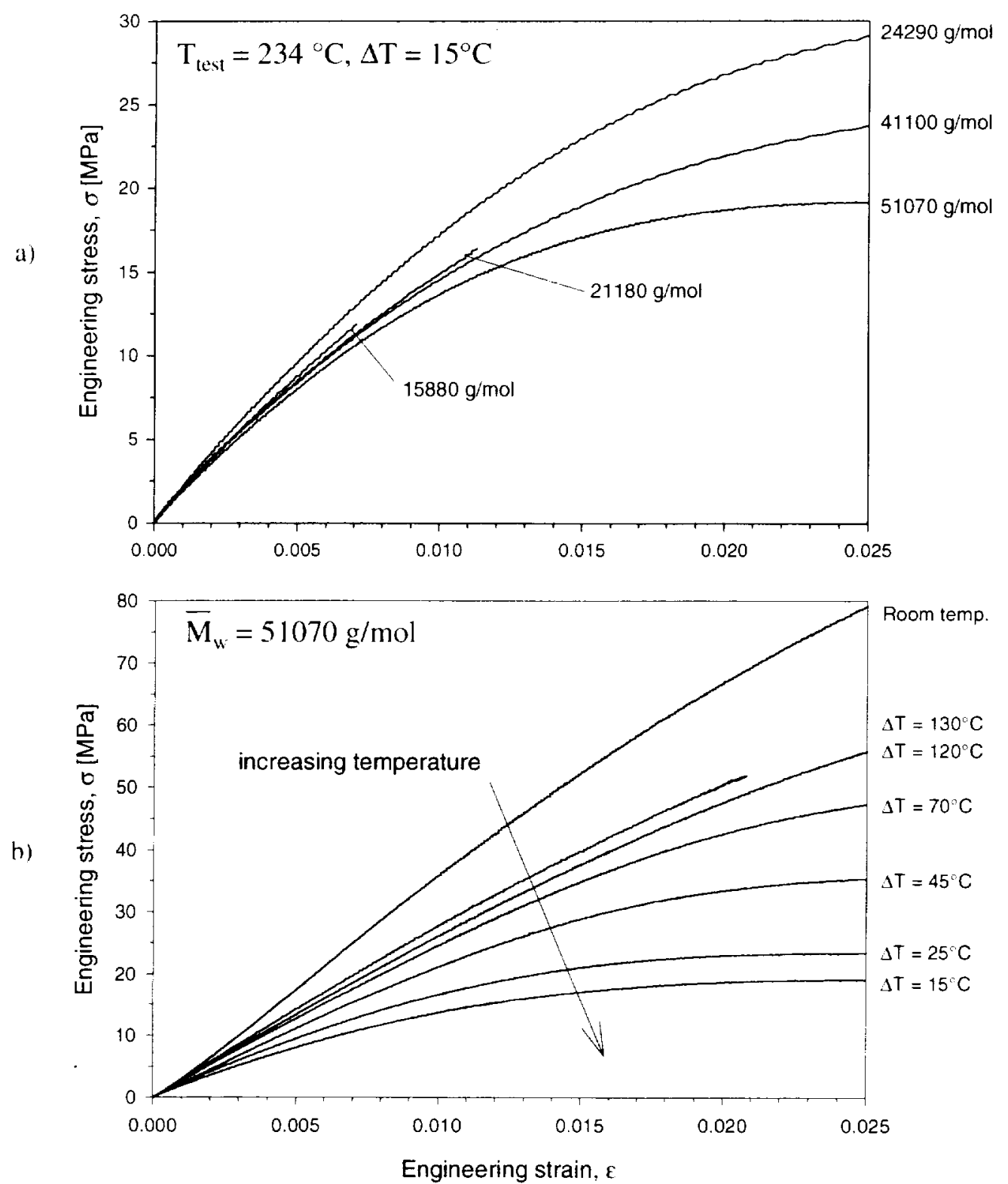

Figure 1. Stress-strain curves for unnotched specimens: (a) of different molecular weights at a reduced test temperature of $15^{\circ} \mathrm{C}$ below $\mathrm{T}_{\mathrm{g}}$; and (b) of high molecular weight $\left(\bar{M}_{w}=51070\right.$ $\mathrm{g} / \mathrm{mol}$ ) displaying the effects of different reduced temperatures. Each curve represents a single test specimen. Curves that terminate before the $2.5 \%$ strain level indicate failure. 
a)

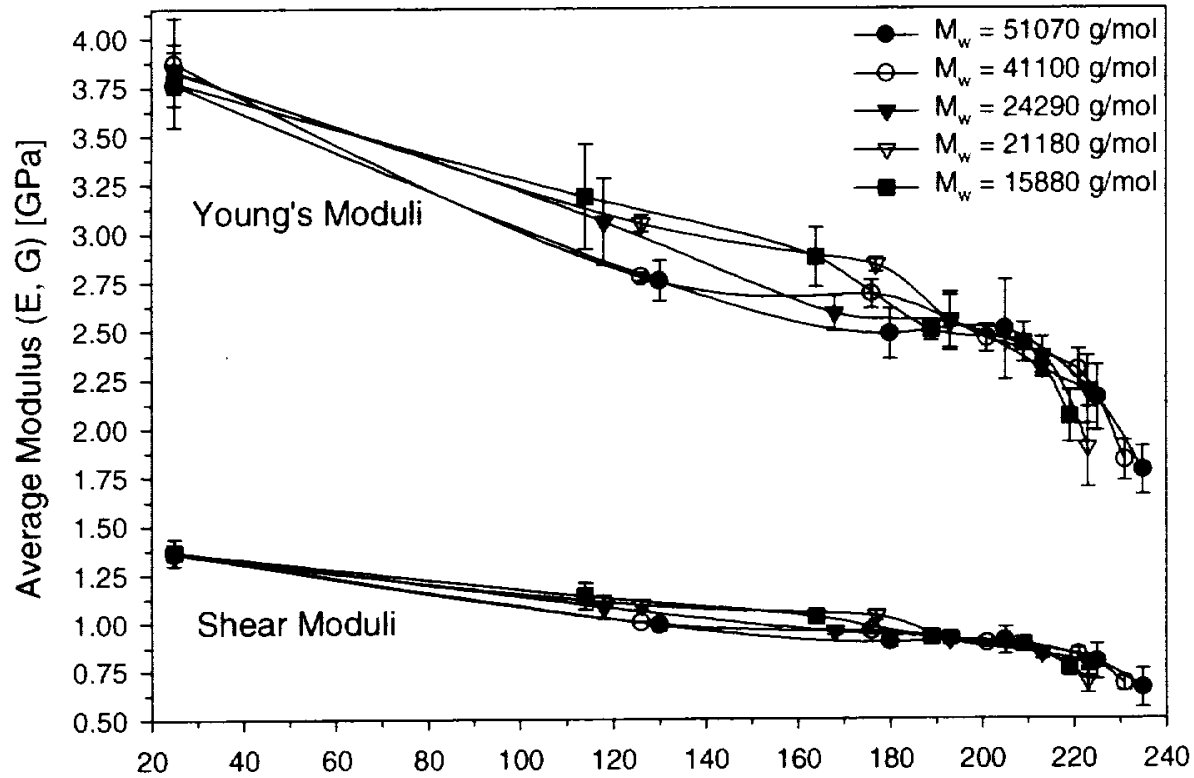

b)

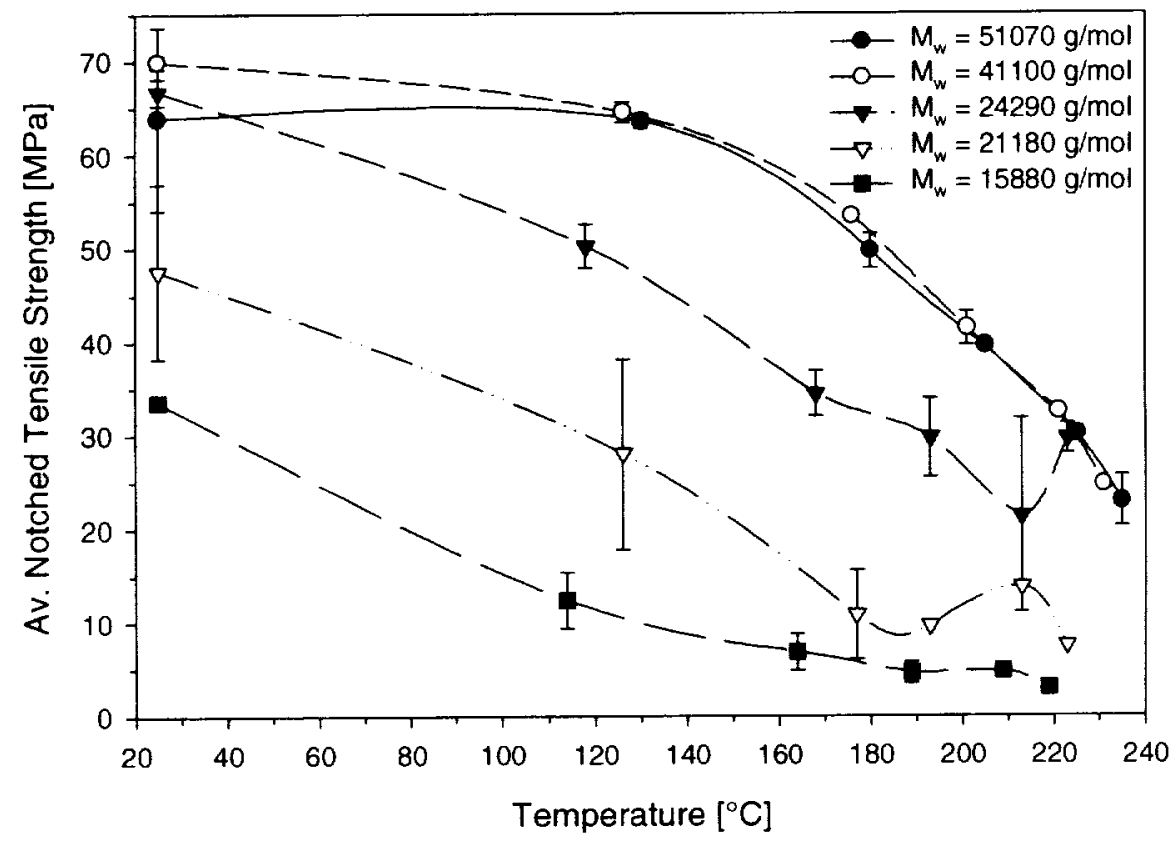

Figure 2. Averaged Young's and Shear Moduli (a) and Averaged Notched Tensile Strength (b) plotted as a function of temperature for various molecular weights. Three test specimens were used to calculate the average Young's and Shear Moduli. Two test specimens were used to calculate the average notched tensile strength. 

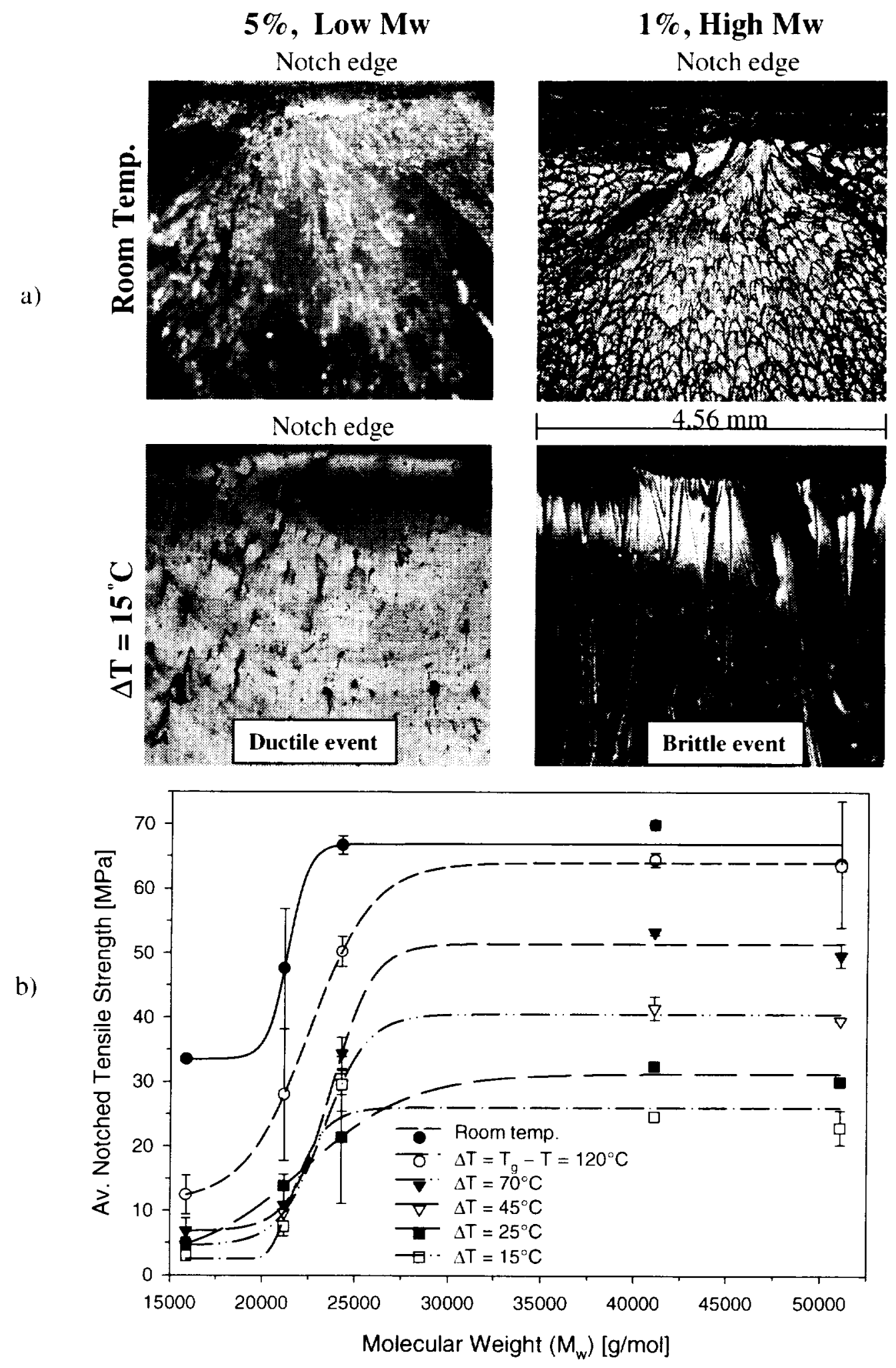

Figure 3. (a) Four optical micrographs of the notched fracture surface at both high and low molecular weights and high and low test temperatures. The notch is at the top of each image, the magnification is $25 \times$. (b) Averaged notched tensile strength plotted as a function of molecular weight at various reduced temperatures. Two test specimens were used to calculate the average notched tensile strength. 
a)

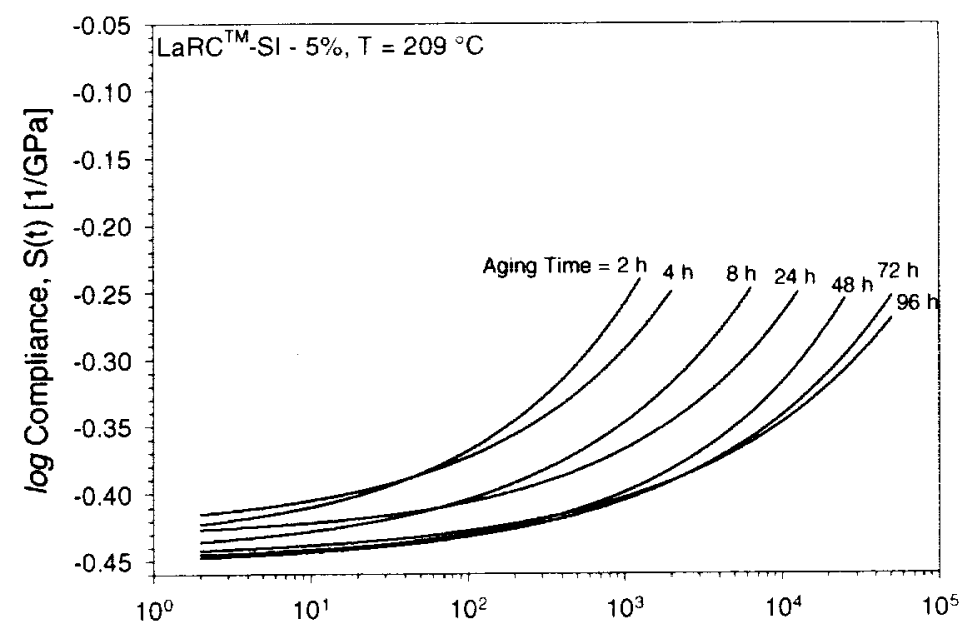

b)

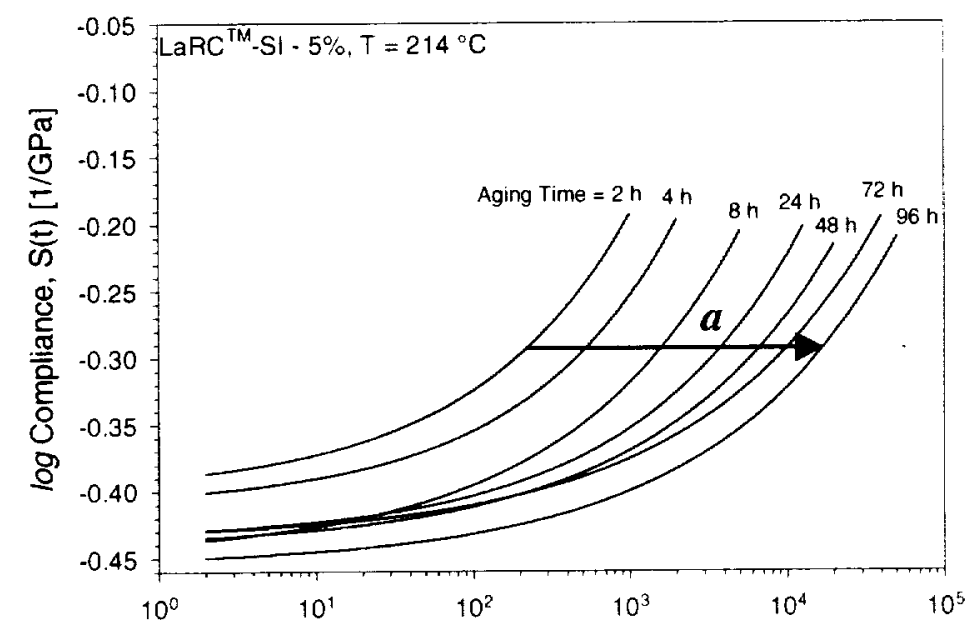

c)

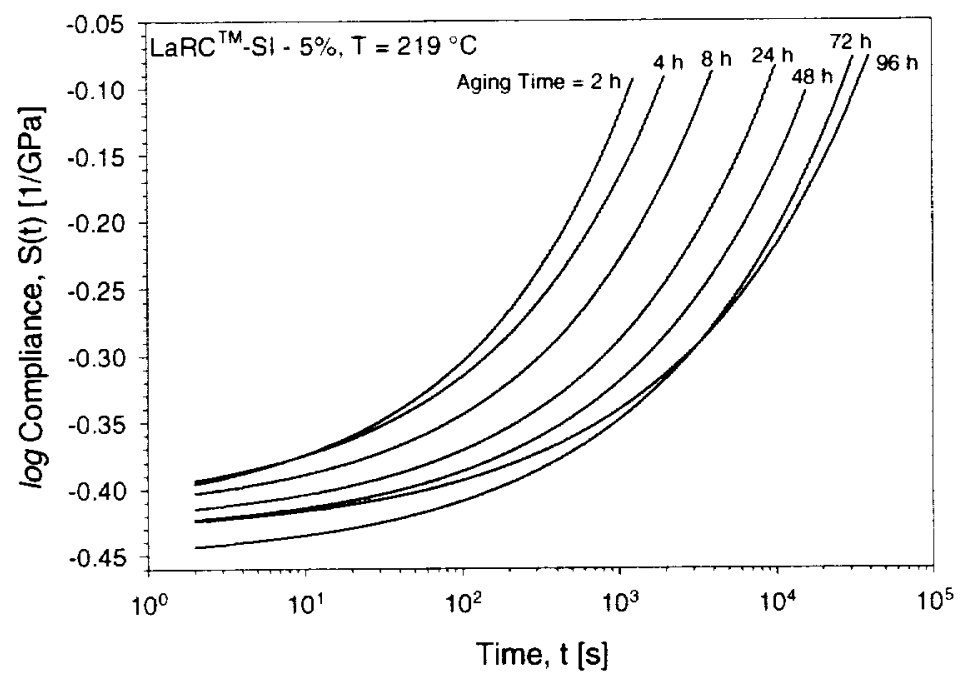

Figure 4. Creep compliance momentary curves plotted as a function of time for the three test temperatures: a) $\mathrm{T}=209^{\circ} \mathrm{C}$, b) $\mathrm{T}=214^{\circ} \mathrm{C}$, c) $\mathrm{T}=219^{\circ} \mathrm{C}$ at $5 \%$ molecular weight offset. The creep compliance momentary curves are shifted to coincide with the $96 \mathrm{~h}$ ageing time reference curve. 
a)
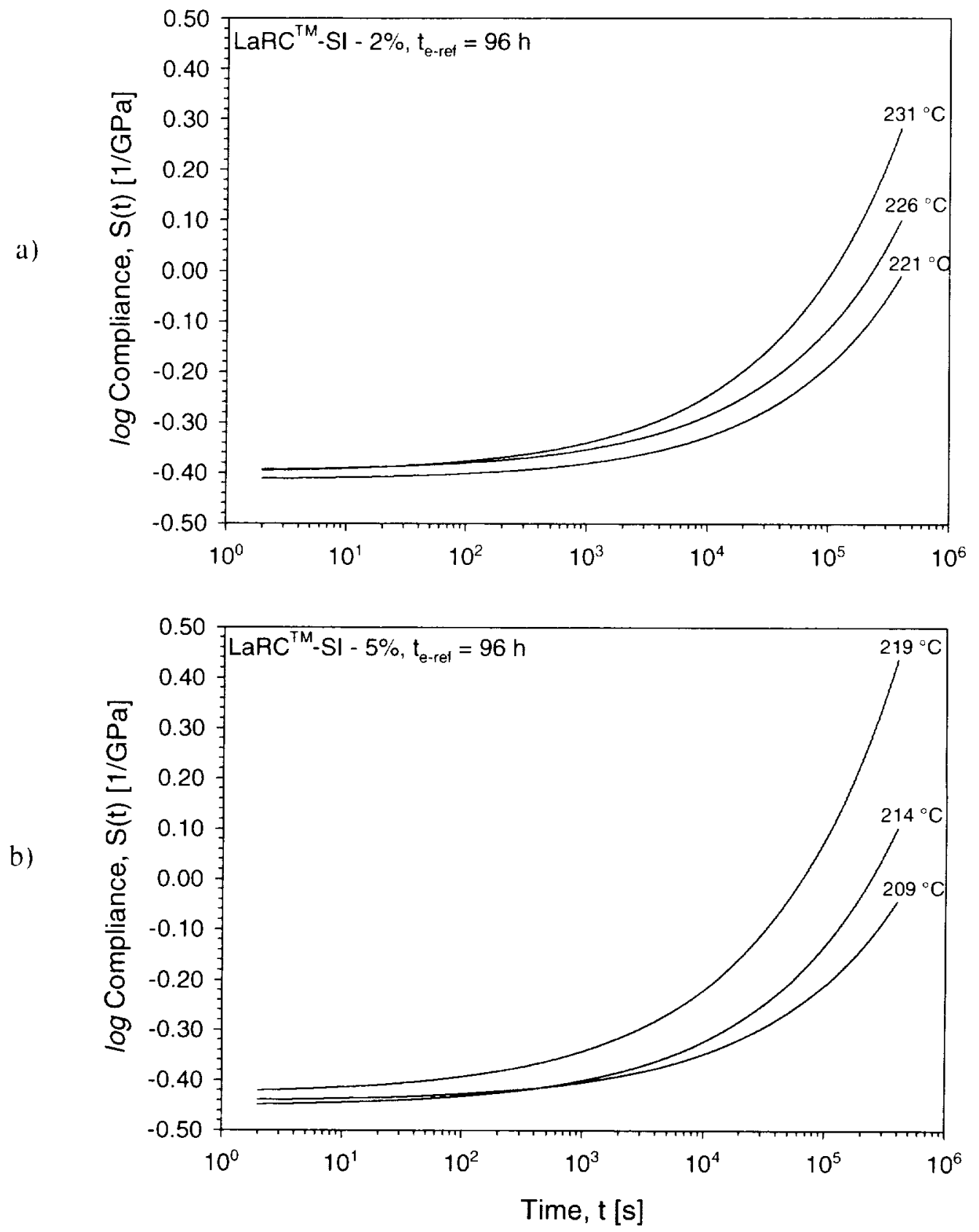

Figure 5. Creep compliance momentary master curves (MMCs) plotted as a function of time for the three test temperatures at high (a) and low (b) molecular weights. The creep compliance momentary curves of Figure 4 were shifted to coincide with the $96 \mathrm{~h}$ ageing time reference curve. 
a)
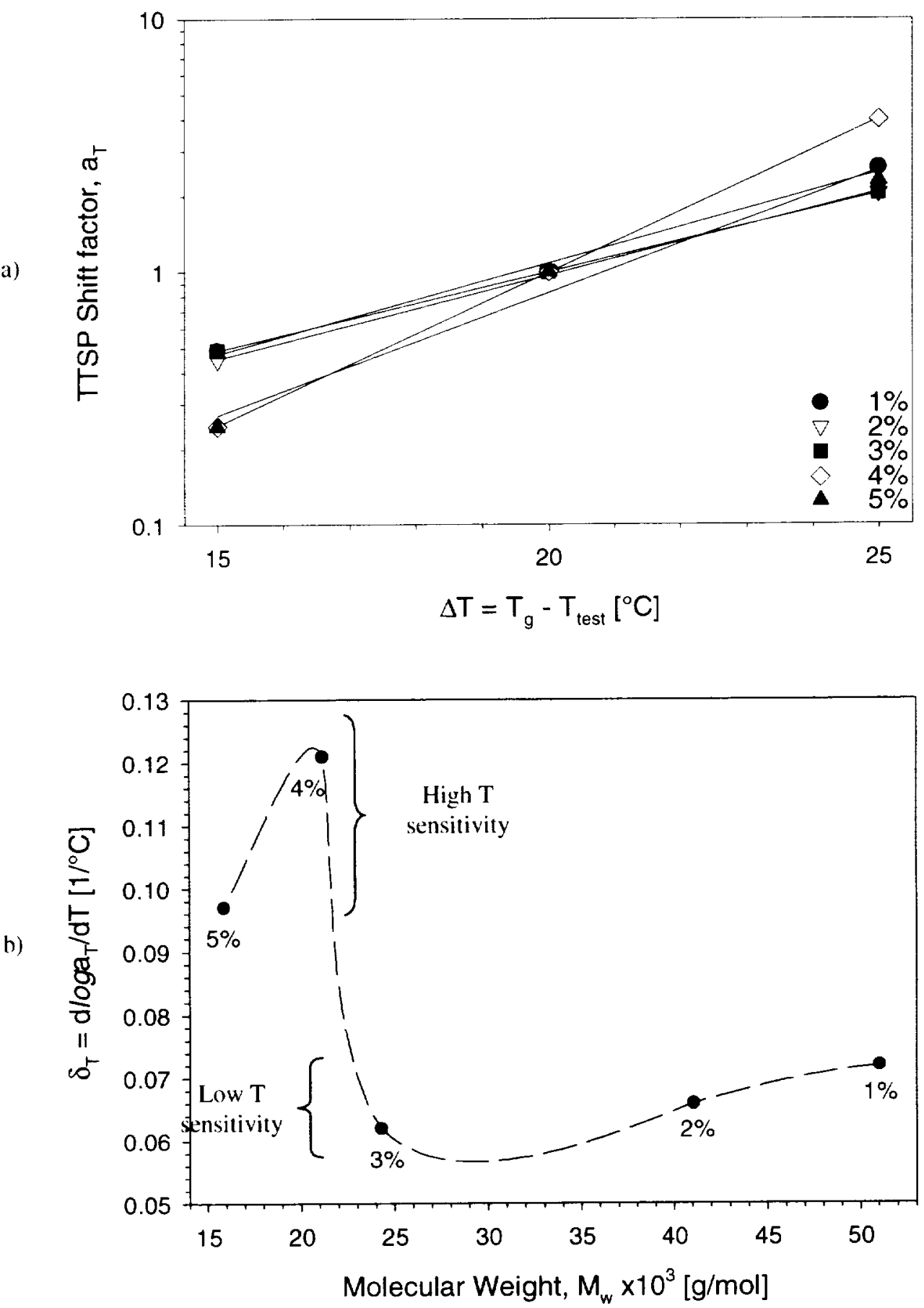

Figure 6. (a) TTSP shift factors plotted as a function of reduced temperature for all molecular weights. The MMCs, for all molecular weights, were shifted horizontally to a reference temperature of $\Delta \mathrm{T}=20^{\circ} \mathrm{C}$. (b) The reduced temperature derivative of TTSP shift factors plotted as a function of molecular weight to indicate the temperature sensitivity of each molecular weight. 


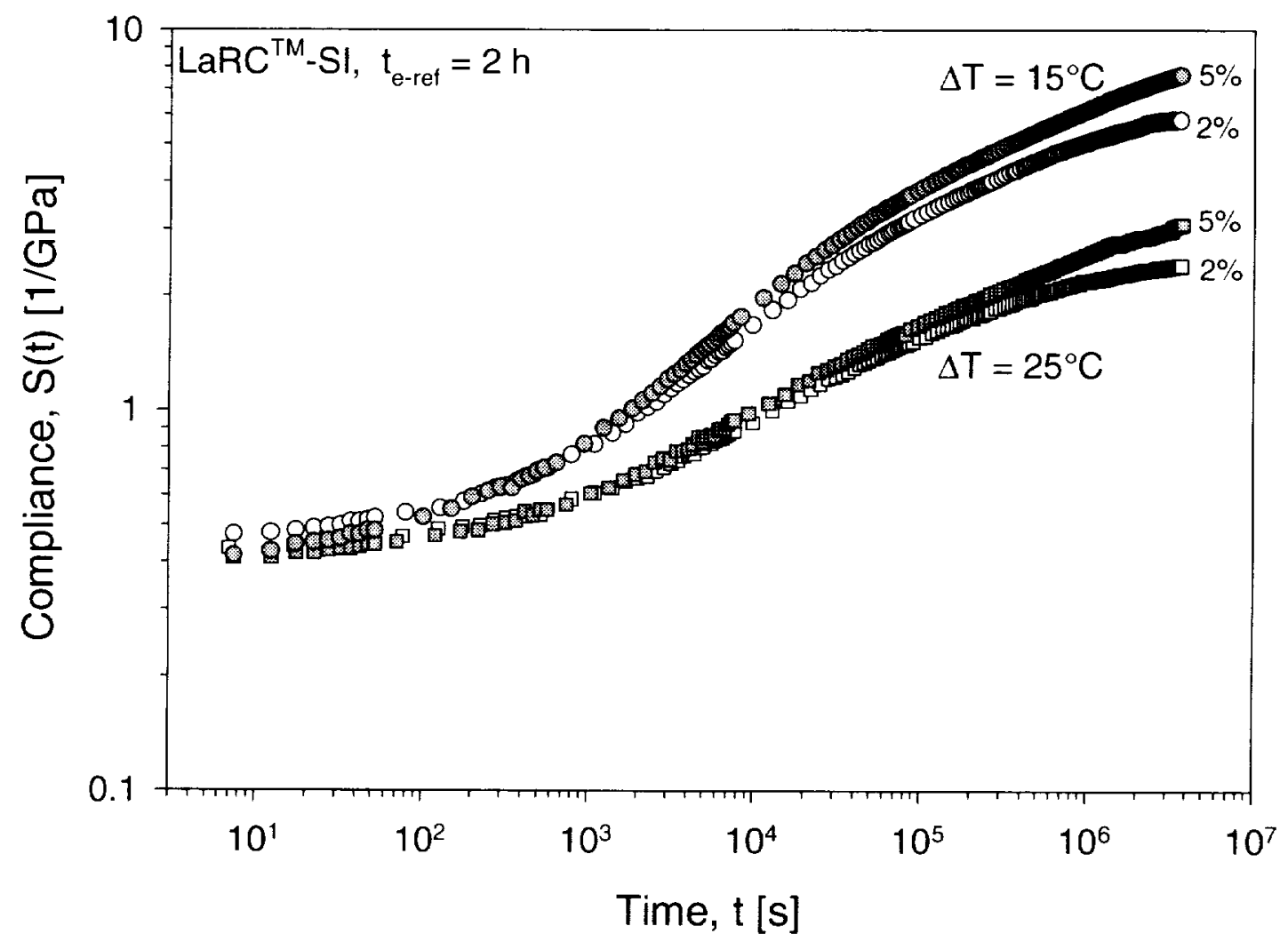

Figure 7. The effect of molecular weight and test temperature on the long-term viscoelastic response. 


\begin{tabular}{|c|c|c|c|c|}
\hline \multicolumn{3}{|c|}{ REPORT DOCUMENTATION PAGE } & & $\begin{array}{l}\text { Form Approved } \\
\text { OMB NO. } 0704-0188\end{array}$ \\
\hline \multicolumn{5}{|c|}{ 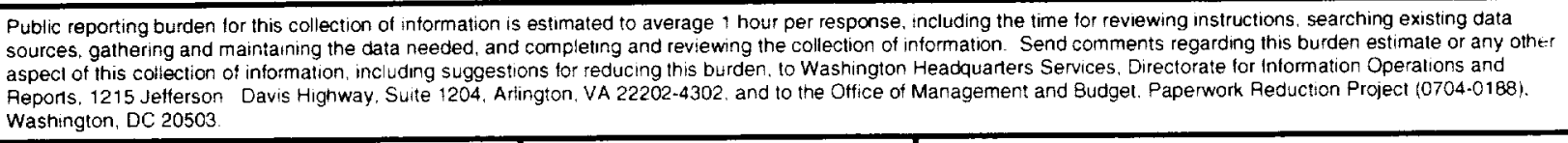 } \\
\hline 1. AGENCY USE ONLY (Leave blank) & \multicolumn{2}{|l|}{$\begin{array}{l}\text { 2. REPORT DATE } \\
\text { February } 2001\end{array}$} & \multicolumn{2}{|c|}{$\begin{array}{l}\text { 3. REPORT TYPE AND DATES COVERED } \\
\text { Technical Memorandum }\end{array}$} \\
\hline \multicolumn{3}{|c|}{$\begin{array}{l}\text { 4. TITLE AND SUBTITLE } \\
\text { The Role of Molecular Weight and Temperature on the Elastic and } \\
\text { Viscoelastic Properties of a Glassy Thermoplastic Polyimide }\end{array}$} & \multirow{2}{*}{\multicolumn{2}{|c|}{$\begin{array}{l}\text { 5. FUNDING NUMBERS } \\
706-1.3-31-02\end{array}$}} \\
\hline \multicolumn{3}{|c|}{$\begin{array}{l}\text { 6. AUTHOR(S) } \\
\text { Lee M. Nicholson, Karen S. Whitley and Thomas S. Gates }\end{array}$} & & \\
\hline \multicolumn{3}{|c|}{$\begin{array}{l}\text { 7. PERFORMING ORGANIZATION NAME(S) AND ADDRESS(ES) } \\
\text { NASA Langley Research Center } \\
\text { Hamplon, VA } 23681-2199\end{array}$} & \multicolumn{2}{|c|}{$\begin{array}{l}\text { 8. PERFORMING ORGANIZATION } \\
\text { REPORT NUMBER }\end{array}$} \\
\hline \multicolumn{3}{|c|}{ 9. SPONSORING/MONITORING AGENCY NAME(S) AND ADDRESS(ES) } & \multicolumn{2}{|c|}{$\begin{array}{l}\text { 10. SPONSORING/MONITORING } \\
\text { AGENCY REPORT NUMBER } \\
\text { NASA/TM-2001-210664 }\end{array}$} \\
\hline \multicolumn{5}{|c|}{$\begin{array}{l}\text { 11. SUPPLEMENTARY NOTES } \\
\text { Dr. Lee M. Nicholson held a National Research Council Research Associateship at NASA Langley Research } \\
\text { Center at the time this work was performed. }\end{array}$} \\
\hline \multicolumn{3}{|c|}{$\begin{array}{l}\text { 12a. DISTRIBUTION/AVAILABILITY STATEMENT } \\
\text { Unclassified-Unlimited } \\
\text { Subject Category } 27 \quad \text { Distribution: Standard } \\
\text { Availability: NASA CASI (301) 621-0390 }\end{array}$} & \multicolumn{2}{|c|}{ 12b. DISTRIBUTION CODE } \\
\hline \multicolumn{5}{|c|}{$\begin{array}{l}\text { 13. ABSTRACT (Maximum } 200 \text { words) } \\
\text { Mechanical testing of the elastic and viscoelastic response of an advanced thermoplastic polyimide (LaRC-SI) } \\
\text { with known variations in molecular weight was performed over a range of temperatures below the glass } \\
\text { transition temperature. The notched tensile strength was shown to be a strong function of both molecular weight } \\
\text { and temperature, whereas stiffness was only a strong function of temperature. A critical molecular weight was } \\
\text { observed to occur at a weight-average molecular weight of } 22,000 \mathrm{~g} / \mathrm{mol} \text { below which, the notched tensile } \\
\text { strength decreases rapidly. This critical molecular weight transition is temperature-independent. Low molecular } \\
\text { weight materials tended to fail in a brittle manner, whereas high molecular weight materials exhibited ductile } \\
\text { failure. Furthermore, low molecular weight materials have increased creep compliance and creep compliance } \\
\text { rate, and are more sensitive to temperature than the high molecular weight materials. At long timescales (>1100) } \\
\text { hours) physical ageing serves to significantly decrease the creep compliance and creep rate of all the materials } \\
\text { tested. Low molecular weight materials are less influenced by the effects of physical ageing. }\end{array}$} \\
\hline \multirow{2}{*}{\multicolumn{4}{|c|}{$\begin{array}{l}\text { 14. SUBJECT TERMS } \\
\text { Polyimides, thermoplastic, glassy, molecular weight, high-temperature, } \\
\text { creep compliance, physical aging, viscoelastic, durability, }\end{array}$}} & $\begin{array}{l}\text { 15. NUMBER OF PAGES } \\
24\end{array}$ \\
\hline & & & & $\begin{array}{l}\text { 16. PAICE CODE } \\
\mathrm{A} 03\end{array}$ \\
\hline $\begin{array}{l}\text { 17. SECURITY CLASSIFICATION } \\
\text { OF REPORT } \\
\text { Unclassified }\end{array}$ & $\begin{array}{l}\text { 18. SECURTYY CLASSIFICATION } \\
\text { OF THIS PAGE } \\
\text { Unclassified }\end{array}$ & $\begin{array}{r}\text { 19. SECURITY } \\
\text { OF ABST } \\
\text { Unclass }\end{array}$ & ATION & $\begin{array}{l}\text { 20. LIMITATION } \\
\text { OF ABSTRACT } \\
\text { UL }\end{array}$ \\
\hline
\end{tabular}

